\title{
Practical Cooling Strategies During Continuous Exercise in Hot Environments: A Systematic Review and Meta-Analysis
}

\author{
Alan Ruddock ${ }^{1} \cdot$ Brent Robbins $^{1} \cdot$ Garry Tew $^{2} \cdot$ Liam Bourke $^{3} \cdot$ Alison Purvis $^{4}$
}

Published online: 1 August 2016

(c) The Author(s) 2016. This article is published with open access at Springerlink.com

\begin{abstract}
Background Performing exercise in thermally stressful environments impairs exercise capacity and performance. Cooling during exercise has the potential to attenuate detrimental increases in body temperature and improve exercise capacity and performance.

Objective The objective of this review was to assess the effectiveness of practical cooling strategies applied during continuous exercise in hot environments on body temperature, heart rate, whole body sweat production, rating of perceived exertion (RPE), thermal perception and exercise performance.

Methods Electronic database searches of MEDLINE, SPORTDiscus, Scopus and Physiotherapy Evidence Database (PEDro) were conducted using medical subject headings, indexing terms and keywords. Studies were eligible if participants were defined as 'healthy', the exercise task was conducted in an environment $\geq 25^{\circ} \mathrm{C}$, it used a cooling strategy that would be practical for athletes to use during competition, cooling was applied during a selfpaced or fixed-intensity trial, participants exercised
\end{abstract}

Alan Ruddock

a.ruddock@shu.ac.uk

1 Centre for Sport and Exercise Science, Sheffield Hallam University, A016 Collegiate Hall, Sheffield S10 2BP, UK

2 Department of Sport, Exercise and Rehabilitation, Northumbria University, Room 244 Northumberland Building, Newcastle upon Tyne NE1 8ST, UK

3 Centre for Sport and Exercise Science, Sheffield Hallam University, A121 Collegiate Hall, Sheffield S10 2BP, UK

4 Faculty of Health and Wellbeing, Sheffield Hallam University, F616 Robert Winston Building, Sheffield S10 2BP, UK continuously, and the study was a randomised controlled trial with the comparator either a thermoneutral equivalent or no cooling. Data for experimental and comparator groups were meta-analysed and expressed as a standardised mean difference and $95 \%$ confidence interval.

Results Fourteen studies including 135 participants met the eligibility criteria. Confidence intervals for meta-analysed data included beneficial and detrimental effects for cooling during exercise on core temperature, mean skin temperature, heart rate and sweat production during fixedintensity exercise. Cooling benefited RPE and thermal perception during fixed-intensity exercise and improved self-paced exercise performance.

Conclusion Cooling during fixed-intensity exercise, particularly before a self-paced exercise trial, improves endurance performance in hot environments by benefiting RPE and thermal perception, but does not appear to attenuate increases in body temperature.

\section{Key Points}

Meta-analyses revealed unclear effects for cooling during exercise on mean core temperature, endexercise core temperature, mean skin temperature, mean heart rate, whole body sweat production and stand-alone self-paced performance.

Cooling during exercise was beneficial for self-paced exercise performance when cooling was applied during a period of fixed-intensity exercise before the trial.

Rating of perceived exertion and thermal perception were also improved and are likely mediators of performance during continuous exercise. 


\section{Introduction}

Sporting events are frequently scheduled in hot and humid environments (e.g. stages of the Tour de France, summermonth marathons); thus evidence-based practical strategies that can alleviate increases in body temperature, reduce the risk of heat illness and improve performance are of interest to scientists and applied practitioners. During cellular respiration, heat produced in active muscle is transferred by conduction and convection to blood and surrounding tissues $[1,2]$. At the skin surface, heat must be transferred via dry and evaporative mechanisms to the environment to limit heat storage and increases in body temperature. When the rate of metabolic heat production exceeds the rate of external heat transfer [1], which frequently occurs when exercise is combined with high ambient temperature $\left(>25^{\circ} \mathrm{C}\right)$ and water vapour pressure, heat is stored and body temperature increases.

Performing exercise in thermally stressful environments increases the risk of exercise-associated muscle cramps, heat syncope, exhaustion, heat injury and exertional heat stroke [3] and also impairs exercise capacity and performance [4-11]. During fixed-intensity exercise, the attainment of high brain [12] and body temperature [5] and subsequent cardiovascular demands limit exercise capability [13]. In contrast, during self-paced exercise performance, external force production is limited so that the task can be completed, possibly mediated through rating of perceived exertion (RPE) [2], skin temperature [14, 15], skin wettedness [16] and thermal sensation [2, 17].

Cooling the body has been the subject of several reviews [18-22], two of which $[18,19]$ investigated the effects of cooling during exercise and suggested that cooling improved endurance performance in the heat. Siegel and Laursen [21], however, noted that most cooling methods are largely impractical for use during competition, a view supported by Tyler et al. [19], who recognised that some cooling methods would be unsuitable for use during performance because of their mass, potential for irritability, and sports regulations. Nevertheless, previous reviews $[18,19]$ included strategies that would be impractical to use during continuous exercise performance (e.g. heavy ice vests, mechanically circulated cool water and fan-assisted head cooling); although these might be useful during intermittent exercise, care needs to be taken when contextualising analyses.

Tyler et al. [19] noted that the largest improvements in performance were observed when core temperature and heart rate were both reduced by cooling, but acknowledged that further research is required to ascertain the mechanisms that explain these performance improvements. This mechanistic underpinning of performance has been identified as an important step in translational physiology [23].

Accordingly, the primary research questions were:

- In healthy participants, does practical cooling during continuous exercise in a hot environment, attenuate mean and final core temperature responses compared with a thermoneutral or no cooling condition in randomised cross-over trials?

- In healthy participants, does practical cooling during continuous exercise in a hot environment, improve selfpaced endurance performance and exercise capacity compared with a thermoneutral or no cooling condition in randomised cross-over trials?

Secondary research questions sought to investigate the effects of cooling during exercise on mean skin temperature, heart rate, whole body sweat production, RPE and thermal perception, all of which have been implicated in the regulation of performance during exercise in the heat.

\section{Methods}

This review was conducted in accordance with the Preferred Reporting Items for Systematic Reviews and MetaAnalyses (PRISMA) statement [24].

\subsection{Inclusion and Exclusion Criteria}

Studies were included if:

- The participants were defined as 'healthy' or 'ablebodied' and without disability or disease that influenced exercise capability or thermoregulation.

- The study was conducted in an environment where the air temperature was $\geq 25^{\circ} \mathrm{C}$.

- The study used a cooling strategy that would be practical for athletes to apply during competitive performance.

- Cooling was applied during a self-paced performance trial or fixed-intensity task.

- The participants exercised continuously.

- The study was a randomised controlled trial with the comparator either being administered at a temperature from 30 to $40{ }^{\circ} \mathrm{C}$ or a no cooling trial.

- The study assessed core body temperature, skin temperature, heart rate, sweat loss, RPE, thermal comfort/ perception, exercise capacity or self-paced performance as an outcome.

- The study was original research published in the English language in peer-reviewed journals (including ahead of press/online first). 
We did not exclude studies based upon exercise mode or sex, but did exclude studies that were designed exclusively to investigate fluid balance. We received no funding for translation services, so only research published in the English language was included within the review.

\subsection{Information Sources and Search Strategy}

Initial electronic database searches were performed up to 10 March 2015 using MEDLINE, SPORTDiscus, Scopus and Physiotherapy Evidence Database (PEDro). The electronic database search was updated on 17 May 2016. Medical subject headings (MeSH), database indexing terms, keywords and Boolean operators (AND/OR) were used in the search strategy. Terms were grouped into themes related to cooling, exercise and body temperature regulation. For SPORTDiscus, search terms included 'cool*', 'cold*', 'cold temperature', 'cryotherapy', 'exercise', 'physical fitness', 'exercise therapy', 'physical exertion', 'sports', 'exercise movement techniques', 'core temperature', 'rectal or oesophageal or esophageal or intest* or tympanic AND temperature', 'body temperature', 'body temperature regulation', 'thermosen*', 'thermor*', 'hypothermia', 'hyperthermia'. All searches were conducted by the same author (AR). Search results were collated using Endnote software (Thomson Reuters, New York), and duplicates were removed. The title and abstract of the remaining studies were screened for relevance (AR). Full texts of potentially appropriate studies were obtained and independently assessed for eligibility by two authors (AR/BR) according to the inclusion criteria. Reference lists and citations (via Google Scholar search) of manuscripts and relevant review articles were examined for potentially eligible studies (AR).

\subsection{Data Extraction Process}

Study characteristics including sample size, age, body mass, stature, aerobic capacity, health status, exercise mode, intensity of exercise, duration of exercise, ambient temperature and humidity, air/wind speed and description of the intervention were extracted for selected studies (AR). Means and standard deviations of the primary (core temperature and self-paced performance) and secondary outcomes (mean skin temperature, heart rate, whole body sweat production, RPE and thermal perception) for experimental and comparator groups were extracted (AR). When relevant data were not reported in the text, they were extracted from figures using GetGraph Graph Digitizer (http://www.getdata-graph-digitizer.com/index.php) by one author (AR). Validity of data extraction was verified by another author (BR). When there was reference to but no pertinent data available from the manuscript, the authors were contacted (AR). Reviewers (AR/BR) were not blinded to authors or institutions at any stage of the selection or data collection process.

\subsection{Data Items}

Core temperature $\left({ }^{\circ} \mathrm{C}\right)$ was a primary outcome and defined as an assessment at either rectal, intestinal, oesophageal or tympanic sites. Mean skin temperature $\left({ }^{\circ} \mathrm{C}\right)$ was defined as at least a four-site weighted assessment using skin surface thermometry. Heart rate (beats. $\mathrm{min}^{-1}$ ) was defined as an assessment using electrocardiography or short-range telemetry. Whole body sweat loss (1) was defined as the difference in body mass pre to post assessment, taking into account fluid ingestion and urine output. RPE and whole body thermal perception were defined as choices made by participants from a perception scale. Exercise capacity tests were defined as those that had a fixed external or internal intensity applied until volitional exhaustion. Self-paced exercise performance was defined as tests whereby the participant was free to choose external intensity over a predetermined duration, distance or set amount of external mechanical work.

\subsection{Risk of Bias in Individual Studies}

Risk of bias was assessed using the 6-point Cochrane Risk of Bias assessment tool [25]. Two authors (AR/BR) independently assessed risk of bias. Appraisal of study quality was performed according to subject expertise (led by AR) and guided by the risk of bias assessment tool.

\subsection{Summary Measures}

The mean and standard deviation of participant physical characteristics, health status, intensity and duration of exercise and exercise mode were used to subjectively determine methodological heterogeneity prior to metaanalysis (AR/BR). Data for experimental and comparator groups were analysed using Cochrane Collaboration's Review Manager 5.3 (Cochrane IMS, Melbourne, Australia). Data were expressed as a standardised mean difference (adjusted Hedges' $g$ ) and $95 \%$ confidence interval (CI). If the $95 \%$ CI included zero, we concluded there was no effect. Statistical heterogeneity was assessed using the $I^{2}$ statistic to determine the percentage of the variability in effect estimates due to heterogeneity rather than sampling error (chance). Pooled intervention effect estimates and $95 \%$ CIs were calculated as a weighted average of the standardised mean difference estimated in individual studies. When $I^{2}$ exceeded $40 \%$ (moderate heterogeneity), a random-effects model was used to calculate the pooled intervention effect; otherwise it was calculated using fixed- 
effect inverse variance. We performed a sensitivity analysis on self-paced performance trials after we found that studies had either (1) performed fixed-intensity exercise before performance trials [e.g. $60 \%$ maximum aerobic capacity $\left(\dot{V} \mathrm{O}_{2 \max }\right)$ for $60 \mathrm{~min}$ followed immediately by a time-trial] or (2) used self-paced performance trials only. Exercise to exhaustion, however, was considered to have large methodological heterogeneity for intensity and duration of exercise and was not meta-analysed.

\section{Results}

\subsection{Participants and Included Studies}

Figure 1 details the PRISMA [24] flow chart. Participant characteristics are detailed in Table 1 and study details in Table 2. Mean fixed intensity was $63 \pm 7 \%$ of $\dot{V} \mathrm{O}_{2 \max }$, and mean duration of exercise was $74 \pm 23 \mathrm{~min}$, consisting of running ( $n=7$ studies) and cycling $(n=7)$ as modes of exercise. Mean ambient temperature, relative humidity and wind speed were $31 \pm 2{ }^{\circ} \mathrm{C}, 52 \pm 17 \%$ and $2.9 \pm 3.5 \mathrm{~m} \cdot \mathrm{s}^{-1}$, respectively. Participant characteristics, intensity, duration and mode of exercise and environmental conditions were considered to have small between-study methodological heterogeneity; thus a meta-analysis was performed on outcomes assessed using fixed-intensity exercise. Self-paced performance trials consisted of cycling ( $n=4$ studies) and running $(n=2)$; the mean duration of these trials was $32.6 \pm 36.3 \mathrm{~min}$ (range from 15 to $97.4 \mathrm{~min})$.

\subsection{Mean and End-Exercise Core Temperature}

Ten outcomes from eight studies [26-33] were included in the meta-analysis for mean core temperature. Six studies used rectal temperature to assess core temperature and two studies used gastrointestinal pills. Studies used ice slurry ( $n=5)$, cold fluid $(n=2)$, ice slurry mouthwash $(n=1)$, neck cooling $(n=1)$ and palm cold pack $(n=1)$ as interventions. There was no effect of cooling on mean core temperature during exercise [Hedges' $g=-0.08(95 \%$ CI -0.37 to 0.22 )] (Fig. 2).

Thirteen outcomes from ten studies [26-29, 31, $32,34-36,39$ ] were included in the meta-analysis for endexercise core temperature. Nine studies used rectal temperature to assess core temperature and one study used gastrointestinal pills. Studies used neck cooling $(n=5)$, ice slurry $(n=4)$, cold fluid $(n=2)$, ice slurry mouthwash and head/neck cooling (both $n=1$ ) as interventions. There was no effect of cooling on core temperature at the end of exercise [Hedges' $g=-0.21$ (95\% CI -0.47 to 0.04$)$ ] (Fig. 3).

\subsection{Mean Skin Temperature}

Ten outcomes from eight studies [26-32, 39] were included in the meta-analysis for mean skin temperature. All assessments were made using weighted four-site mean calculation [37] via skin surface thermometry. Studies used ice slurry $(n=5)$, cold fluid $(n=2)$, ice slurry mouthwash $(n=1)$, neck cooling and head/neck cooling (both $n=1$ ) as interventions. There was no effect of cooling on mean skin temperature [Hedges' $g=-0.28$ (95\% CI -0.56 to 0.00)] (Fig. 4).

\subsection{Mean Heart Rate}

Seven outcomes from six studies [27, 29-33] were included in the meta-analysis for mean heart rate. Studies used ice slurry ( $n=3$ ), cold fluid, palm cold pack, neck cooling and ice slurry mouthwash (all $n=1$ ) as interventions. There was no effect of cooling on mean heart rate [Hedges' $g=-0.03$ (95\% CI -0.37 to 0.32)] (Fig. 5).

\subsection{Rating of Perceived Exertion and Whole Body Thermal Perception}

Eight outcomes from seven studies [27, 31, 33, 34, $36,38,39]$ were included in the meta-analysis for mean RPE. All studies used the Borg 6-20 RPE scale. Studies used neck cooling $(n=4)$, palm cold pack, ice slurry, ice slurry mouthwash and combined forehead and neck cooling (all $n=1$ ) as interventions. Cooling during exercise improved RPE [Hedges' $g=-0.49$ (95\% CI -0.81 to -0.17)] (Fig. 6). Six outcomes from six studies [27, 29-31, 34, 36] were included in the meta-analysis for mean thermal perception. Studies used three different scales [40-42]; one investigation did not report the scale used [31]. Studies used, neck cooling $(n=3)$, ice slurry $(n=2)$ and cold fluid $(n=1)$ as interventions. Cooling during exercise improved thermal perception [Hedges' $g=-0.67$ (95\% CI -1.06 to -0.29$)$ ] (Fig. 7).

\subsection{Whole Body Sweat Production}

Six outcomes from five studies [32, 34-36, 39] were included in the meta-analysis for whole body sweat production. Studies used neck cooling $(n=4)$, ice slurry and head and neck cooling as interventions (all $n=1$ ). There was no effect of cooling during exercise on whole body sweat production [Hedges' $g=-0.13(95 \% \mathrm{CI}-0.50$ to 0.23)] (Fig. 8). 


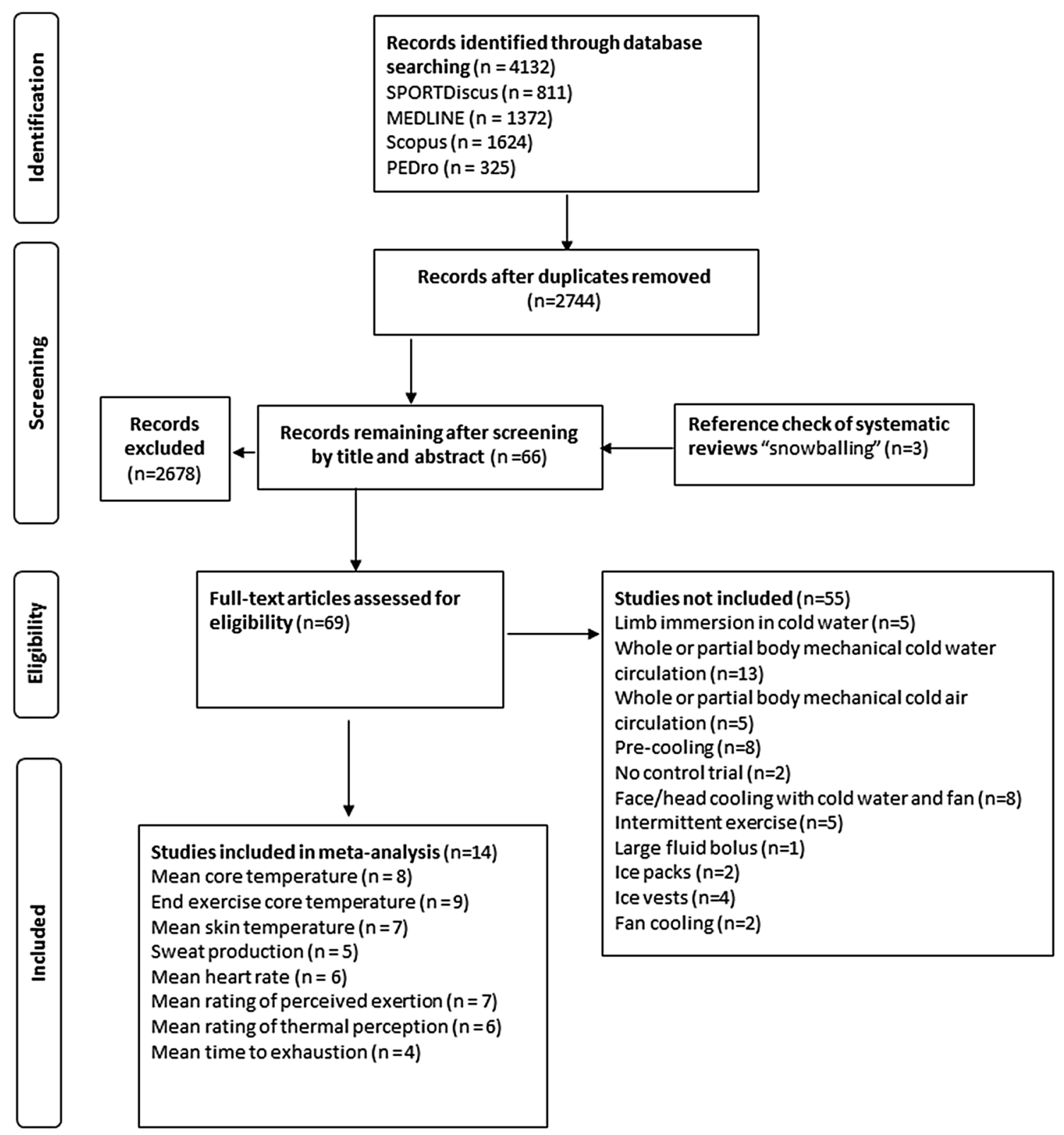

Fig. 1 PRISMA flow diagram. PEDro Physiotherapy Evidence Database, PRISMA Preferred Reporting Items for Systematic Reviews and MetaAnalyses

\subsection{Exercise Duration}

Four studies assessed time to exhaustion at a fixed intensity. Two studies reported mean improvements in time to exhaustion using neck cooling; however, CIs suggested no effect was observed [Hedges' $g=-0.38(95 \% \mathrm{CI}-1.37$ to 0.61$) ; g=-0.58$ (95\% CI -1.40 to 0.24 ), respectively] [31, 34]. One study used a palm cold pack [33] and reported no effect on time to exhaustion during running [Hedges' $g=-0.07$ (95\% CI -0.87 to 0.73 )] and another used cold fluid [29] and documented no effect on time to exhaustion during cycling [Hedges' $g=-0.09$ (95\% CI -1.07 to 0.89$)]$.

\subsection{Self-Paced Performance}

Eleven outcomes from six studies [26, 27, 30, 35, 36, 43] were included in the meta-analysis for self-paced performance. Studies used neck cooling $(n=4)$, cold fluid ingestion $(n=3)$, ice slurry $(n=3)$ and ice slurry mouthwash $(n=1)$ as interventions. There was a beneficial effect of cooling during exercise on self-paced 
Table 1 Characteristics of participants in included studies

\begin{tabular}{|c|c|c|c|c|c|c|}
\hline Study & $\begin{array}{l}\text { Number of } \\
\text { participants }\end{array}$ & $\begin{array}{l}\text { Age } \\
\text { (years) }\end{array}$ & $\begin{array}{l}\text { Body mass } \\
(\mathrm{kg})\end{array}$ & $\begin{array}{l}\text { Stature } \\
(\mathrm{cm})\end{array}$ & $\begin{array}{l}\dot{V} \mathrm{O}_{2 \max } \\
\left(\mathrm{ml} \cdot \mathrm{kg}^{-1} \cdot \min ^{-1}\right)\end{array}$ & Characterisation \\
\hline Burdon et al. (2010) [26] & 7 & $33 \pm 6$ & $81.1 \pm 11.1$ & $183 \pm 9$ & $59.4 \pm 6.6$ & Non-acclimated males \\
\hline Burdon et al. (2013) [27] & 10 & $30 \pm 7$ & $75.1 \pm 9.4$ & & $61.8 \pm 5.6$ & $\begin{array}{l}\text { Healthy, naturally acclimatised male } \\
\text { endurance cyclists }\end{array}$ \\
\hline Burdon et al. (2015) [28] & 10 & $30 \pm 7$ & $75.1 \pm 9.4$ & $175 \pm 7$ & $61.8 \pm 5.6$ & $\begin{array}{l}\text { Healthy, naturally acclimatised male } \\
\text { endurance cyclists and triathletes }\end{array}$ \\
\hline Lee et al. (2008) [29] & 8 & $27 \pm 4$ & $70.9 \pm 7.9$ & $174 \pm 5$ & $53.8 \pm 6.2$ & Non-heat acclimated males \\
\hline Lee et al. (2014) [31] & 12 & $24 \pm 2$ & $61.6 \pm 8.1$ & $172 \pm 5$ & $59.4 \pm 5.3$ & Healthy males \\
\hline Minniti et al. (2011) [38] & 8 & $25 \pm 5$ & $77.4 \pm 5.6$ & $181 \pm 8$ & $53.7 \pm 4.7$ & Healthy males \\
\hline Morris et al. (2015) [32] & 9 & $25 \pm 5$ & $75.9 \pm 12.2$ & $177 \pm 7$ & $50.9 \pm 8.5$ & Healthy males \\
\hline Scheadler et al. (2013) [33] & 12 & $23 \pm 4$ & $76.1 \pm 8.7$ & $179 \pm 6$ & $53.8 \pm 5.2$ & Healthy males \\
\hline Schulze et al. (2015) [30] & 7 & $33 \pm 8$ & $73.1 \pm 3.3$ & $179 \pm 5$ & $61.7 \pm 3.0$ & Well trained male triathletes \\
\hline Tyler et al. (2010) [36] ${ }^{\mathrm{a}}$ & 9 & $25 \pm 4$ & $76.5 \pm 5.9$ & $181 \pm 7$ & $54.2 \pm 4.6$ & Healthy males \\
\hline Tyler et al. (2010) [36] ${ }^{\mathrm{a}}$ & 8 & $25 \pm 3$ & $75.5 \pm 7.0$ & $180 \pm 5$ & $54.9 \pm 3.1$ & Healthy males \\
\hline $\begin{array}{l}\text { Tyler and Sunderland (2011) } \\
\text { [34] }\end{array}$ & 8 & $26 \pm 2$ & $77 \pm 6.2$ & $177 \pm 6$ & $56.2 \pm 9.2$ & Endurance trained athletes \\
\hline $\begin{array}{l}\text { Tyler and Sunderland (2011) } \\
\text { [35] }\end{array}$ & 7 & $25 \pm 2$ & $75.3 \pm 8.4$ & $179 \pm 5$ & $55.3 \pm 3.6$ & Healthy males \\
\hline Bulbulian et al. (1999) [39] & 10 & $27 \pm 6$ & $80.5 \pm 6.7$ & $181 \pm 4$ & $38.6 \pm 6.3$ & Healthy active males \\
\hline Carvalho et al. (2014) [43] & 10 & $25 \pm 6$ & $69 \pm 2.7$ & $170 \pm 10$ & $67.2 \pm 1.8$ & $\begin{array}{l}\text { Well trained male athletes (cyclists, } \\
\text { mountain bikers, triathletes) }\end{array}$ \\
\hline
\end{tabular}

Data presented as mean $\pm \mathrm{SD}$

$S D$ standard deviation, $\dot{V} O_{2 \max }$ maximum aerobic capacity

a Two-part experiment

performance [Hedges' $g=-0.48$ (95\% CI -0.78 to -0.18)] (Fig. 9). Sensitivity analysis demonstrated that self-paced performance was improved after fixed-intensity exercise [Hedges' $g=-0.47$ (95\% CI -0.83 to -0.12$)$ ] (Fig. 9), but the effect was only evident following a fixedintensity pre-load and not for self-paced performance trials only.

\section{Discussion}

The purpose of this review was to investigate the effects of practical cooling strategies used during continuous exercise in hot environments. Meta-analyses revealed no effect for cooling during exercise on mean core temperature, endexercise core temperature, mean skin temperature, mean heart rate, whole body sweat production and stand-alone self-paced performance; although CIs for these estimates overlapped beneficial and detrimental effects, suggesting uncertainty in the point estimate, we interpret these findings as being unclear and that more data are required to improve confidence in the interpretation of these outcomes. Cooling during exercise, however, was beneficial for self- paced exercise performance when cooling was applied during a period of fixed-intensity exercise before the trial; RPE and thermal perception were also improved by cooling. The unclear effects on stand-alone self-paced performance and improved RPE and thermal perception oppose findings from previous meta-analyses [18, 19]. These studies found clear improvements in performance but unclear findings for perceptual responses. These contradictions are likely due to differences in study selection.

Our systematic search strategy identified 14 studies that met our inclusion criteria, whereas a previous meta-analysis included up to nine studies [19]. Tyler et al. [19] noted that some cooling methods might have limited practicality (e.g. excess mass, skin irritation and sport-rule constraints); thus we only included studies that were deemed to be practically applicable during continuous exercise. We excluded studies that used 'face/head fan or water cooling', 'liquid/air cooling garments', 'partial limb water immersion', 'ice cooling vests', and 'fluid bolus $>400 \mathrm{ml}$ '; these strategies were deemed to be impractical, especially during competition. Studies utilising these methods, however, were included in the two previous meta-analyses on cooling during exercise [18, 19]. Bongers et al. [18] and Tyler 
Table 2 Details of included studies that used fixed-intensity exercise

\begin{tabular}{|c|c|c|c|c|c|c|c|}
\hline Study & $\begin{array}{l}\text { Exercise } \\
\text { mode }\end{array}$ & $\begin{array}{l}\text { Intensity } \\
(\% \\
\left.\dot{V} \mathrm{O}_{2 \max }\right)\end{array}$ & $\begin{array}{l}\text { Duration } \\
(\mathrm{min})\end{array}$ & $\begin{array}{l}\text { Ambient } \\
\text { temperature } \\
\left({ }^{\circ} \mathrm{C}\right)\end{array}$ & $\begin{array}{l}\text { Relative } \\
\text { humidity } \\
(\%)\end{array}$ & $\begin{array}{l}\text { Air } \\
\text { speed } \\
(\mathrm{m} / \mathrm{s})\end{array}$ & Intervention \\
\hline Burdon et al. (2010) [26] & Cycling & 65 & 90 & 28.0 & 70.0 & 1.0 & $\begin{array}{l}2.3 \mathrm{ml} \cdot \mathrm{kg}^{-1}(185 \mathrm{ml}) \text { every } 10 \text { min of } 4{ }^{\circ} \mathrm{C} \\
7.4 \% \text { carbohydrate-electrolyte solution. } \\
37{ }^{\circ} \mathrm{C} 7.4 \% \text { carbohydrate-electrolyte } \\
\text { solution. } 37{ }^{\circ} \mathrm{C} 7.4 \% \text { carbohydrate- } \\
\text { electrolyte solution }+30 \mathrm{ml} \text { ice slurry } \\
\left(-1{ }^{\circ} \mathrm{C}\right) \text { every } 5 \mathrm{~min}\end{array}$ \\
\hline Burdon et al. (2013) [27] & Cycling & 62 & 90 & 32.1 & 40.0 & 1.0 & $\begin{array}{l}260 \pm 38 \mathrm{~g} \text { of } 7.4 \% \text { carbohydrate- } \\
\text { electrolyte solution every } 10 \text { min as either } \\
\text { ice slurry }\left(-1{ }^{\circ} \mathrm{C}\right) \text { or thermoneutral } \\
\left(37^{\circ} \mathrm{C}\right)\end{array}$ \\
\hline Burdon et al. (2015) [28] & Cycling & 62 & 90 & 32.0 & 40.0 & 1.0 & $\begin{array}{l}260 \pm 38 \mathrm{~g} \text { of } 7.4 \% \text { carbohydrate- } \\
\text { electrolyte solution every } 10 \text { min as either } \\
\text { ice slurry }\left(-1{ }^{\circ} \mathrm{C}\right) \text { or thermoneutral } \\
\left(37^{\circ} \mathrm{C}\right)\end{array}$ \\
\hline Lee et al. (2008) [29] & Cycling & 50 & 90 & 25.3 & 60.0 & & $\begin{array}{l}400 \mathrm{ml} \text { of } 10 \text { or } 37^{\circ} \mathrm{C} \text { water ingested at } 30, \\
45,60 \text { and } 75 \mathrm{~min} \text { of exercise }\end{array}$ \\
\hline Lee et al. (2014) [31] & Running & 70 & 75 & 30.2 & 71.0 & & $\begin{array}{l}\text { 155-g neck cooling collar worn throughout. } \\
\text { No neck cooling collar }\end{array}$ \\
\hline Minniti et al. (2011) [38] & Running & 60 & 75 & 30.4 & 53.0 & & $\begin{array}{l}\text { 155-g neck cooling collar worn throughout. } \\
\text { Uncooled collar }\end{array}$ \\
\hline Morris et al. (2015) [32] & Cycling & 55 & 75 & 33.5 & 23.7 & 2.25 & $\begin{array}{l}3.2 \mathrm{mg} \cdot \mathrm{kg}^{-1}(240 \mathrm{ml}) \text { or } 37^{\circ} \mathrm{C} \text { of ice slurry } \\
\text { ingested at } 15 \text {-min intervals for first } \\
45 \mathrm{~min} \text { of exercise }\end{array}$ \\
\hline Scheadler et al. (2013) [33] & Running & 75 & 53 & 30.0 & 50.0 & & $\begin{array}{l}\text { Refrigerated gel pack on single palm. No } \\
\text { refrigerated gel pack }\end{array}$ \\
\hline Schulze et al. (2015) [30] & Cycling & & 60 & 30.0 & 80.0 & 9.1 & $\begin{array}{l}\text { Ad libitum ingestion of either } \\
\text { carbohydrate-electrolyte solution ice } \\
\text { slurry }\left(-1^{\circ} \mathrm{C}\right) \text { or thermoneutral beverage } \\
\left(30^{\circ} \mathrm{C}\right)\end{array}$ \\
\hline Tyler et al. (2010) [36] & Running & 60 & 75 & 30.4 & 53.0 & & $\begin{array}{l}\text { 155-g neck cooling collar worn throughout. } \\
\text { Uncooled collar }\end{array}$ \\
\hline $\begin{array}{l}\text { Tyler and Sunderland (2011) } \\
\text { [34] }\end{array}$ & Running & 70 & 41 & 32.2 & 53.0 & & $\begin{array}{l}\text { 155-g neck cooling collar worn throughout. } \\
\text { No cooling collar }\end{array}$ \\
\hline $\begin{array}{l}\text { Tyler and Sunderland (2011) } \\
\text { [35] }\end{array}$ & Running & 60 & 75 & 30.4 & 53 & & $\begin{array}{l}\text { 155-g neck cooling collar worn throughout. } \\
\text { Neck cooling collar replaced at } 30 \text { and } \\
60 \text { min. No cooling collar }\end{array}$ \\
\hline Bulbulian et al. (1999) [39] & Cycling & 60 & 30 & 30 & 25 & 8.9 & $\begin{array}{l}\text { Headband and neck cooling collar soaked } \\
\text { in ice water. No cooling }\end{array}$ \\
\hline
\end{tabular}

$\dot{V} O_{2 \max }$ maximum aerobic capacity

et al. [19] found that ice jackets had the greatest effect on performance; Tyler et al. [19] recognised this and subsequently offered an alternative mean-weighted standardised difference estimate with the ice jacket study [44] excluded from their analysis. However, this was because the study was conducted in an uncompensable environment, not because of the unsuitability of ice jackets.

Tyler et al. [19] did not include cold water or ice slurry ingestion in their analysis; however, we chose to include these methods because they are practical methods during continuous exercise in the heat. Bongers et al. [18] included one cold water ingestion study in their analysis [45], but the comparator to the experimental trial $\left(4^{\circ} \mathrm{C}\right)$ was also cold fluid $\left(19^{\circ} \mathrm{C}\right)$ and not thermoneutral; thus it was not included in the present meta-analysis. Moreover, it is unclear whether a criterion for inclusion in the previous meta-analyses required a thermoneutral or no cooling comparator trial. Whilst we recognise that studies might be investigating 'applied' practices, using a thermoneutral trial as a comparator is preferable to understand the true effect of cooling during exercise, particularly the mechanisms of action, which is an important component of translational physiology [23]. 


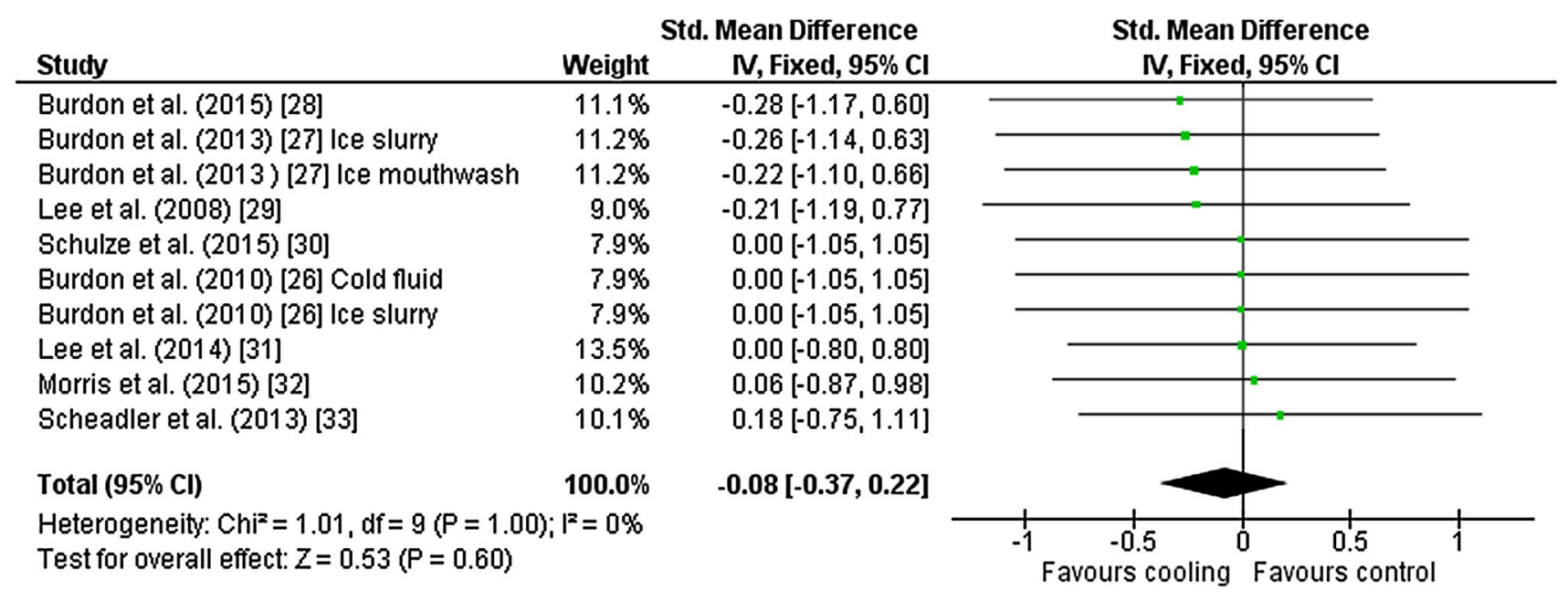

Fig. 2 Intervention effect estimates, $95 \%$ CIs and weighted average of the Std for mean core temperature. $C I$ confidence interval, $I V$ inverse variance, $S D$ standard deviation, $S t d$ standardised mean difference

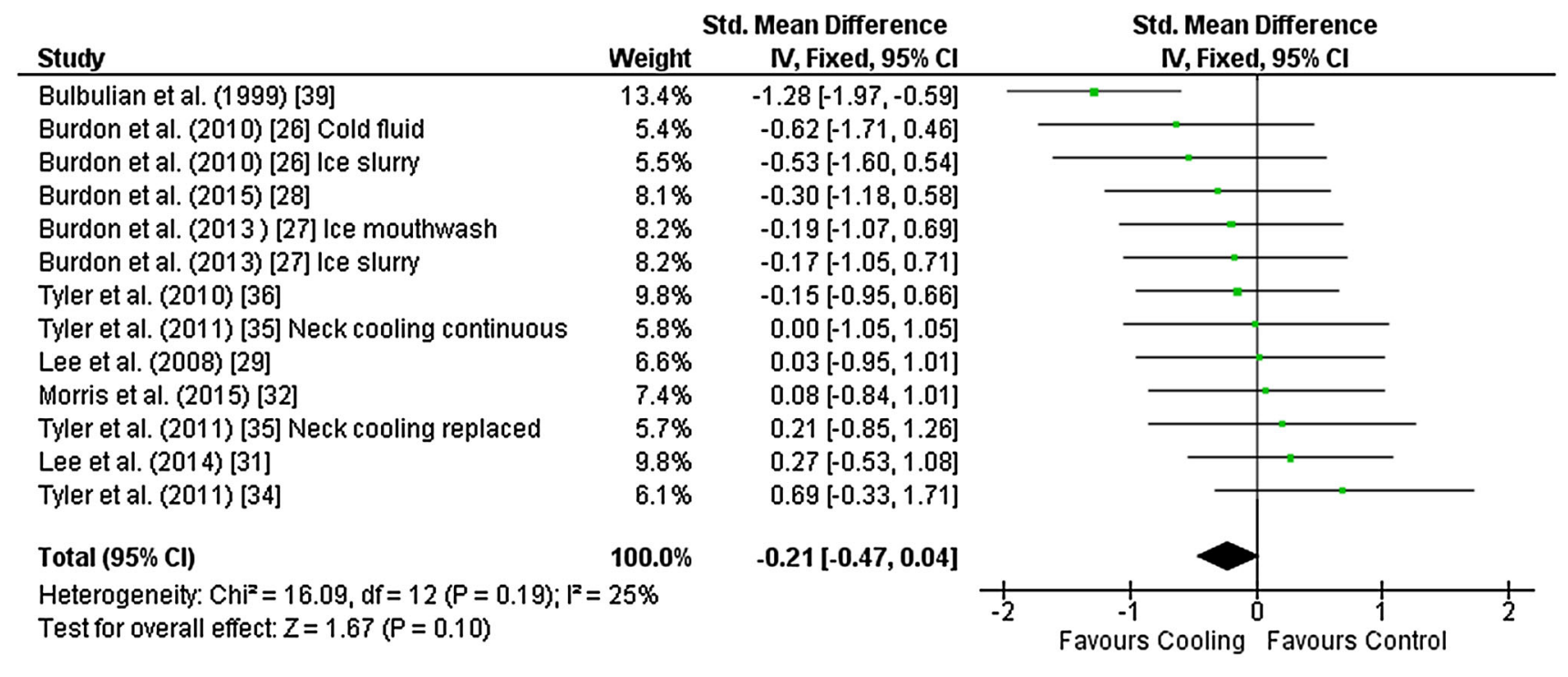

Fig. 3 Intervention effect estimates, $95 \%$ CIs and weighted average of the Std for end-exercise core temperature. $C I$ confidence interval, $I V$ inverse variance, $S D$ standard deviation, $S t d$ standardised mean difference

To understand the mechanistic actions of cooling during exercise, we discriminated between studies that used fixedintensity exercise and self-paced performance trials. During self-paced exercise, participants are free to choose external intensity and regulate performance, but betweentrial differences in intensity make interpretations of thermophysiological data difficult. During fixed-intensity exercise, however, thermophysiological effector responses are forced [46]. Such responses (e.g. core temperature) are typically reliable [47] and enable valid comparisons between interventions. Bongers et al. [18] did not discriminate between fixed-intensity exercise or self-paced performance and it was not the aim of Tyler et al. [19] to do so, but both studies reported thermophysiological responses. This distinction between study designs is a possible explanation for the differences reported in perceptual responses between the present study and that of Tyler et al. [19]. Our analysis indicates that RPE and thermal perception are improved with cooling during fixedintensity exercise; however, Tyler et al. [19] reported unclear findings.

We discriminated between time-to-exhaustion trials and self-paced performance trials, which the two previous meta-analyses did not. These types of test are suggested to be regulated by different mechanisms; in self-paced trials participants are free to choose external intensity, and whilst this choice might have a physiological origin, behaviour is regulated by RPE within acceptable limits for the task [2] 


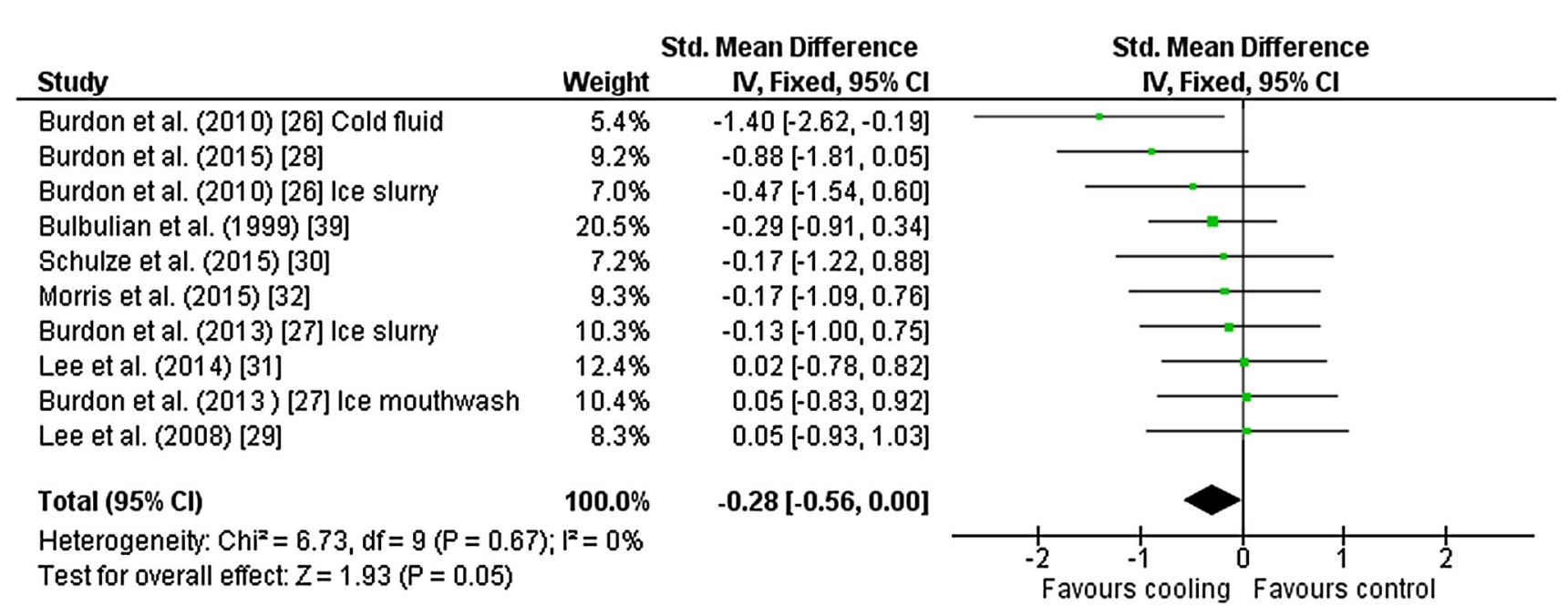

Fig. 4 Intervention effect estimates, $95 \%$ CIs and weighted average of the Std for mean skin temperature. $C I$ confidence interval, $I V$ inverse variance, $S D$ standard deviation, $S t d$ standardised mean difference

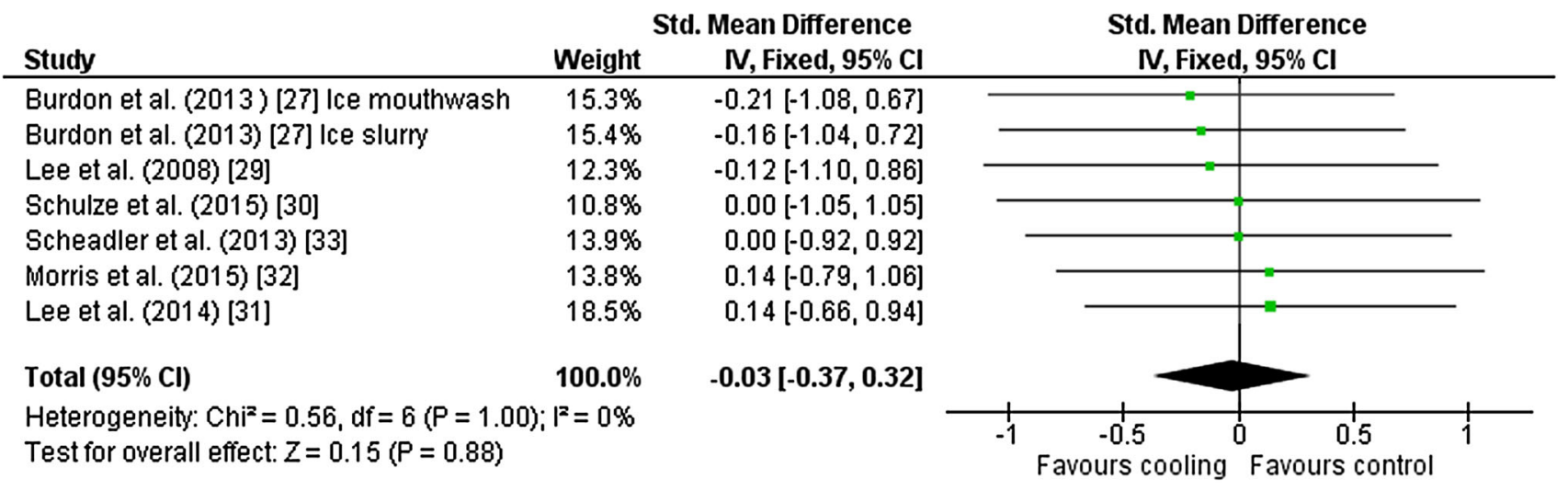

Fig. 5 Intervention effect estimates, $95 \%$ CIs and weighted average of the Std for mean heart rate. $C I$ confidence interval, $I V$ inverse variance, $S D$ standard deviation, $S t d$ standardised mean difference

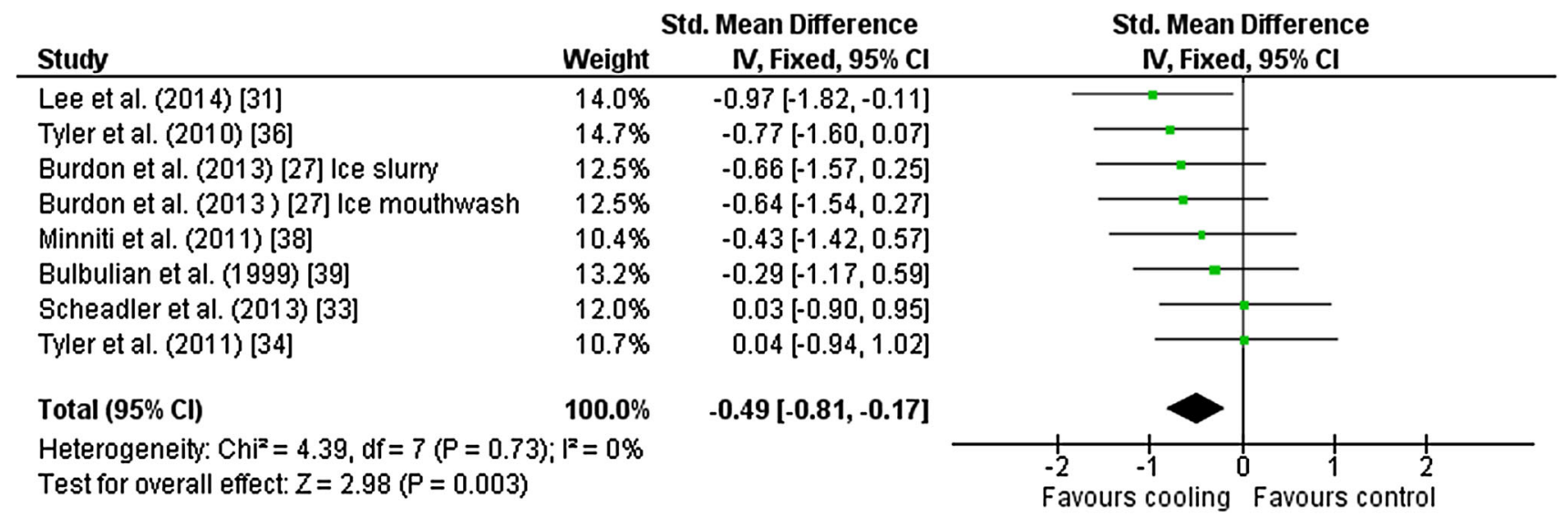

Fig. 6 Intervention effect estimates, $95 \%$ CIs and weighted average of the Std for mean rating of perceived exertion. $C I$ confidence interval, $I V$ inverse variance, $S D$ standard deviation, $S t d$ standardised mean difference 


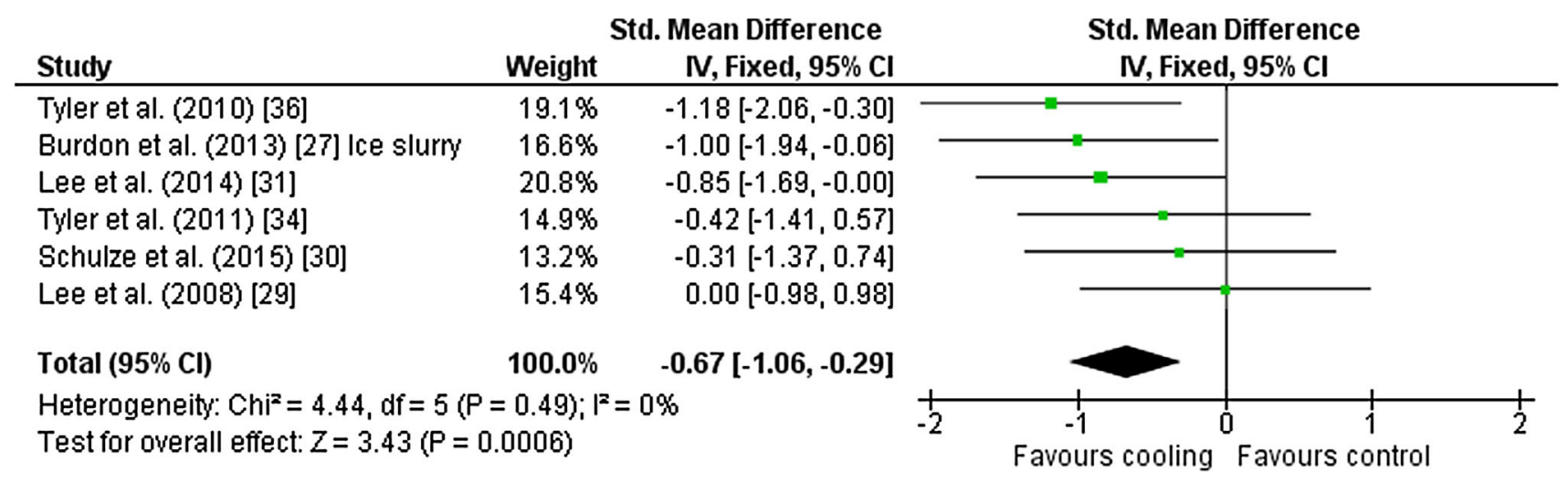

Fig. 7 Intervention effect estimates, $95 \%$ CIs and weighted average of the Std for thermal perception. $C I$ confidence interval, $I V$ inverse variance, $S D$ standard deviation, $S t d$ standardised mean difference

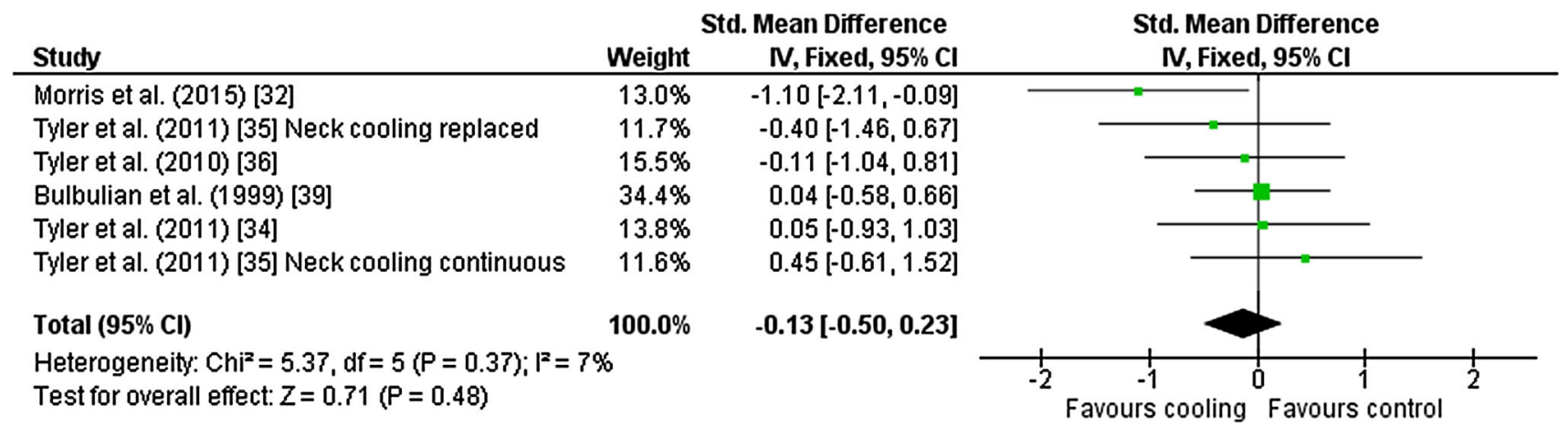

Fig. 8 Intervention effect estimates, $95 \%$ CIs and weighted average of the Std for whole body sweat production. $C I$ confidence interval, $I V$ inverse variance, $S D$ standard deviation, $S t d$ standardised mean difference

to avoid excessive physiological strain. In fixed-intensity exercise, participants cannot freely choose external intensity and the increasing demands on cardiovascular, neuromuscular and central nervous systems as a result of metabolic heat production and heat storage [48] integrate with psychological factors to determine time to exhaustion. Therefore, these types of tests should be analysed separately to avoid confusion in interpretation. Furthermore, it is well established that time-to-exhaustion tests have a greater magnitude of test-retest error than time trials [49] and such variance might contribute to wider CIs resulting in an unclear effect. Indeed, we found unclear effects of neck cooling [31, 34], cold fluid ingestion [29] and a palm cold gel pack [33] on exercise time to exhaustion.

\subsection{Core Temperature}

Bongers et al. [18] suggested that cooling during exercise might attenuate the increase in core temperature, increase heat storage capacity and improve exercise capacity based on the theory for a single terminal tissue temperature ('critical core temperature') for cessation of exercise. This assertion was based upon the purported effectiveness of an 'aggressive' cooling strategy using an ice vest [50]. Ice vests, however, are not practical for use during continuous exercise performance and the mechanistic theory (critical core temperature hypothesis) underpinning this recommendation is likely too simple to explain human behavioural thermoregulation [48, 51]. Nevertheless, we investigated this hypothesis using fixed-intensity exercise trials. None of the practical cooling methods demonstrated clear reductions in either mean or end-exercise core temperature. A possible explanation is that the enthalpy of cooling methods was insufficient or the site at which cooling was applied had limited tissue perfusion (required for effective heat transfer). This might have been the case in cold water and slurry ingestion given the documented reduction in splanchnic blood flow during exercise in the heat [52] and also for neck cooling. Continuous cooling at a site with potential for high rates of perfusion would seem to be an ideal method for attenuating increases in body temperature.

\subsection{Perceptual Responses}

Flouris and Schlader [2] suggested that thermal perception is an important mediator of behavioural thermoregulation 


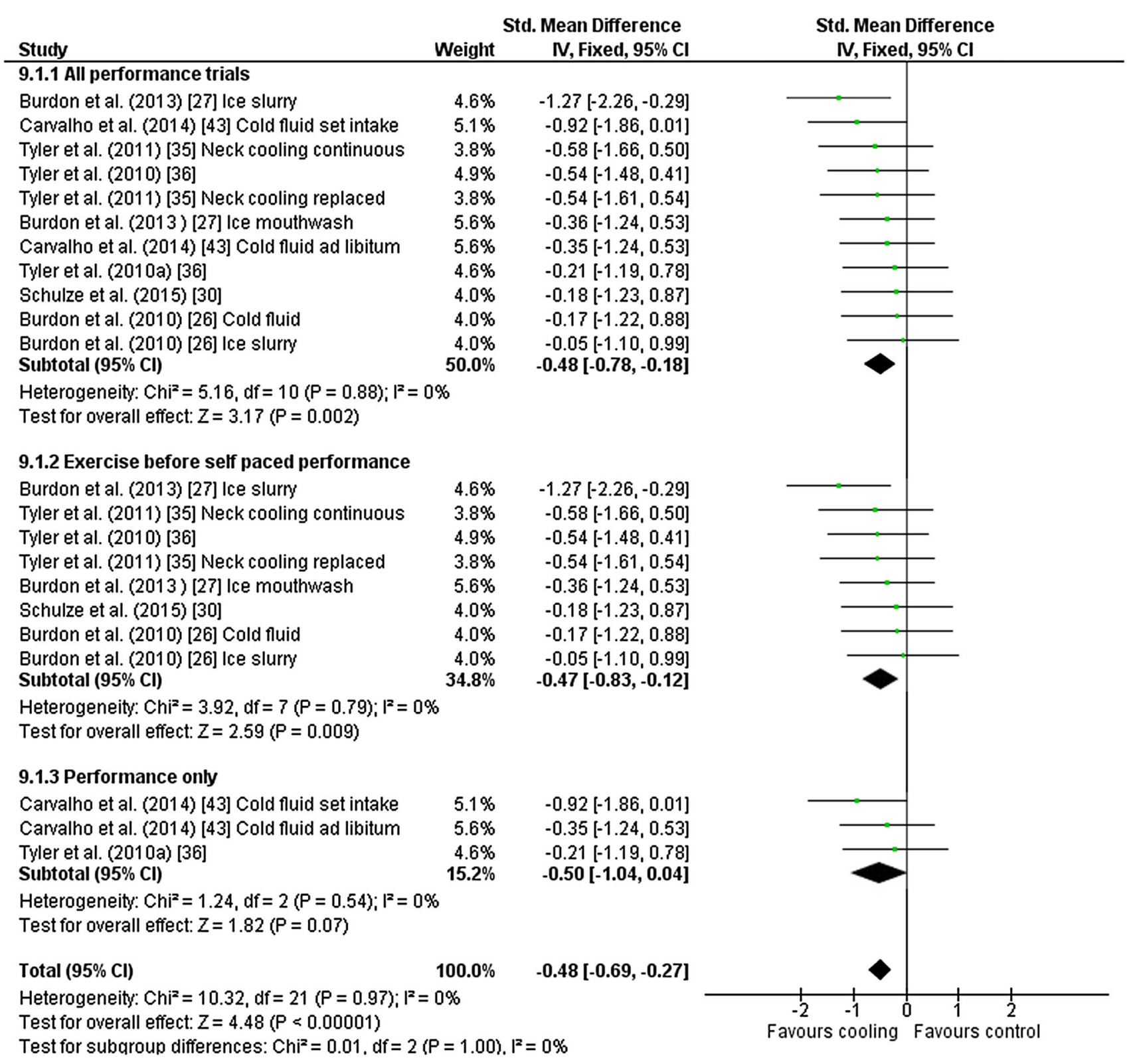

Fig. 9 Intervention effect estimates, $95 \%$ CIs and weighted average of the Std for self-paced performance. 'Tyler et al. [36]' refers to the second experiment reported in the manuscript. CI confidence interval,

that integrates with RPE in its role as the predominant controller of the intensity of exercise. We found that RPE and thermal perception were improved by cooling during fixed-intensity exercise, and this is a key finding from our analysis. Prior to increases in core temperature, self-selected intensity of exercise is likely mediated by thermal perception and its influence on RPE, whereas when core and skin temperature are elevated, cardiovascular strain is a key RPE input [2]. Studies included in the present metaanalysis used neck cooling, ice slurry and fluid ingestion. Cooling the neck during heat exposure elicits feelings of thermal comfort at rest [53], a finding extended to two
$I V$ inverse variance, $S D$ standard deviation, Std standardised mean difference

$[31,36]$ of three studies of neck cooling during exercise. We found an unclear effect for one study [34]; the reason for this is unknown as the neck cooling collar was the same and participants and environmental conditions were similar in all three investigations. The study, however, was designed to investigate time to exhaustion and the final core temperature was $>39{ }^{\circ} \mathrm{C}$; therefore cardiovascular strain might have been the key RPE mediator rather than thermal perception. However, it is worth noting that RPE was similar between conditions. There was also a clear beneficial effect of ice slurry ingestion on thermal perception in one study [27], but not in another [30]. These 
differences might be attributed to the study design, specifically, a beneficial effect of set-planned [27] rather than ad libitum [30] ingestion of slurry. Lee et al. [29] reported similar between-trial responses for thermal perception $\left(400 \mathrm{ml}\right.$ of $10{ }^{\circ} \mathrm{C}$ fluid versus $37^{\circ} \mathrm{C}$ fluid ingested at 15-min intervals), although the mean ambient temperature of $25.3{ }^{\circ} \mathrm{C}$ combined with an intensity of $50 \% \dot{V} \mathrm{O}_{2 \max }$ was among the least thermally stressful of included studies; indeed final core temperature was $38.11{ }^{\circ} \mathrm{C}$, less than the mean of included studies, which was $38.48 \pm 0.58^{\circ} \mathrm{C}$.

Six out of eight studies reported mean improvements for RPE. Standardised mean differences for neck cooling [34] and palm cold pack [33] were similar for experimental and comparator trials. It is unclear whether palm cooling occurred in the latter study [33] because palm skin temperature was not reported; thus absence of cooling might be an explanation for the similar between-trial RPE. Nevertheless, the weighted standardised mean difference and $95 \%$ CI indicate that cooling during exercise has the potential to improve RPE; possibly mediated via beneficial effects of cooling on thermal perception.

\subsection{Performance}

Our findings indicate that cooling during fixed-intensity exercise before a self-paced time trial improves performance (Fig. 9). Strictly, this could be considered cooling before performance, but we included these studies in our analysis because of the number of studies that have classified this type of design as cooling during exercise. These data are informative for those sports whereby 'sub-maximal' intensities precede an intense period of activity, such as in team road cycling. In these circumstances, tactical efforts are used to position a rider (or group) for an 'attack' at key points within a race. Cooling during the sub-maximal phase of the race, whereby fluid ingestion and external cooling aids are less constrained by logistics, might benefit performance in a subsequent 'attack'. In stand-alone self-paced performance trials, there are usually observable 'end spurts', which prior cooling might also benefit; however, we did not investigate pacing profiles in these studies. Furthermore, we found unclear effects of cooling during stand-alone self-paced performance trials, but the three trials included in the metaanalysis all reported mean improvements; a larger sample size would improve the precision of the effect.

\subsection{Skin Temperature and Heart Rate}

We observed unclear effects of cooling during exercise on mean skin temperature and heart rate during fixed-intensity exercise. Burdon et al. [28] investigated a potential link between ice slurry ingestion, decreased skin temperature and heart rate during exercise. Although Burdon et al. [28] reported a statistically significant difference $(P<0.05)$ between ice slurry and thermoneutral trials for mean skin temperature towards the end of $90 \mathrm{~min}$ of cycling at $62 \%$ $\dot{V} \mathrm{O}_{2 \max }$ in $30{ }^{\circ} \mathrm{C}$, our analysis found an unclear effect on mean skin temperature [Hedges' $g=-0.88(95 \% \mathrm{CI}$ -1.81 to 0.05$)$ ] for this study. These unclear effects were replicated across all included studies apart from Burdon et al. [26], where there was a beneficial effect of cold fluid ingestion $\left(4^{\circ} \mathrm{C}, \sim 185 \mathrm{ml}\right.$ every $10 \mathrm{~min}$ for $\left.90 \mathrm{~min}\right)$ on mean skin temperature [Hedges' $g=-1.40(95 \% \mathrm{CI}$ -2.62 to -0.19$)$ ]. There were no beneficial effects on heart rate across the range of included studies (Fig. 5) in the present meta-analysis. This does not, however, indicate there were no beneficial effects on skin blood flow or stroke volume, as skin temperature and heart rate are only indexes of these variables in this context.

The effect of cooling during exercise on whole body sweat rate was unclear (Fig. 8), although one study [32] reported a clear decrease in whole body sweat rate after ingesting $3.2 \mathrm{ml} \cdot \mathrm{kg}^{-1}$ of ice slurry $(\sim 240 \mathrm{ml})$ at three 15-min intervals $(15,30$ and $45 \mathrm{~min})$ during the first $45 \mathrm{~min}$ of $75 \mathrm{~min}$ of exercise. The authors suggested that intra-abdominal thermoreceptors integrate with the central nervous system to elicit strong thermoeffector responses at the skin surface, in particular sudomotor function. Therefore, despite an internal heat sink caused by slurry ingestion, the decreased evaporative heat loss impaired net heat loss and increased heat storage. It should be noted that this was the only study included in the meta-analysis that used ice slurry during exercise to investigate whole body sweat rate responses; more research is required to corroborate these findings.

\subsection{Study Methods and Reporting}

All studies included in the present investigation were randomised cross-over trials; however, it was unclear as to how randomisation and allocation concealment occurred (Table 3). Researchers should report this information to facilitate appraisal of bias and study quality. Some studies (e.g. Tyler and Sunderland [35]) reported changes in local temperature as a result of cooling; however, most studies did not. Tyler et al. [19] recognised that such information is required to confirm whether local cooling occurred as a result of the intervention and is particularly relevant for external cooling methods. In addition, researchers should indicate the practicality of the method and report feelings of uncomfortableness, irritations, adverse effects and general appraisals from participants. This information would be helpful to scientists, coaches and athletes who are in the 
Table 3 Risk of bias assessment

\begin{tabular}{|c|c|c|c|c|c|c|}
\hline Study & $\begin{array}{l}\text { Random sequence } \\
\text { generation }\end{array}$ & $\begin{array}{l}\text { Allocation } \\
\text { concealment }\end{array}$ & $\begin{array}{l}\text { Blinding of participants } \\
\text { and personnel }\end{array}$ & $\begin{array}{l}\text { Blinding of outcome } \\
\text { assessment }\end{array}$ & $\begin{array}{l}\text { Incomplete } \\
\text { outcome data }\end{array}$ & $\begin{array}{l}\text { Selective } \\
\text { reporting }\end{array}$ \\
\hline $\begin{array}{l}\text { Burdon et al. (2010) } \\
\text { [26] }\end{array}$ & $?$ & $?$ & - & $?$ & + & + \\
\hline $\begin{array}{l}\text { Burdon et al. (2013) } \\
\text { [27] }\end{array}$ & $?$ & $?$ & - & $?$ & + & + \\
\hline $\begin{array}{l}\text { Burdon et al. (2015) } \\
\text { [28] }\end{array}$ & $?$ & $?$ & - & $?$ & $?$ & + \\
\hline Lee et al. (2008) [29] & $?$ & $?$ & - & $?$ & $?$ & + \\
\hline Lee et al. (2014) [31] & $?$ & $?$ & - & $?$ & $?$ & + \\
\hline $\begin{array}{l}\text { Minniti et al. (2011) } \\
\text { [38] }\end{array}$ & $?$ & $?$ & - & $?$ & $?$ & + \\
\hline $\begin{array}{l}\text { Morris et al. (2015) } \\
\text { [32] }\end{array}$ & $?$ & $?$ & - & $?$ & $?$ & + \\
\hline $\begin{array}{l}\text { Scheadler et al. } \\
\text { (2013) [33] }\end{array}$ & $?$ & $?$ & - & $?$ & + & + \\
\hline $\begin{array}{l}\text { Schulze et al. (2015) } \\
\text { [30] }\end{array}$ & $?$ & $?$ & - & $?$ & + & + \\
\hline $\begin{array}{l}\text { Tyler et al. (2010) } \\
\text { [36] }\end{array}$ & $?$ & $?$ & - & $?$ & $?$ & + \\
\hline $\begin{array}{l}\text { Tyler and Sunderland } \\
\text { (2011) [34] }\end{array}$ & $?$ & ? & - & ? & $?$ & + \\
\hline $\begin{array}{l}\text { Tyler and Sunderland } \\
\text { (2011) [35] }\end{array}$ & $?$ & $?$ & - & $?$ & $?$ & + \\
\hline $\begin{array}{l}\text { Bulbulian et al. } \\
\text { (1999) [39] }\end{array}$ & $?$ & $?$ & - & $?$ & $?$ & + \\
\hline $\begin{array}{l}\text { Carvalho et al. (2014) } \\
\text { [43] }\end{array}$ & $?$ & $?$ & - & $?$ & $?$ & + \\
\hline
\end{tabular}

+ Low risk of bias, - high risk of bias, ? unclear risk of bias

process of evaluating the suitability of a particular cooling method for their own specific use.

\subsection{Limitations}

A potential limiter to the application of all cooling studies is that there is no consensus as to what constitutes a practical or impractical cooling strategy. The suitability of a particular technique is ultimately based upon complex interplay between the logistical constraints of the situation, coaching philosophy and athlete perceptions. Nevertheless, researchers have investigated strategies that might not be feasible for use during continuous exercise, a problem that has been previously identified in the scientific literature $[19,21]$. In the absence of such consensus, we have excluded strategies that we deem to be impractical for use during actual competition. This might have introduced selection bias within our included studies, but we are confident that we have captured strategies that are useful for athletes, coaches and scientists. Including studies that used impractical strategies would have limited the ecological validity of the present review and thus its applied impact. We acknowledge that the data presented here are based entirely on samples from male participants. There is some evidence indicating a lower sweat rate in females compared with males [54]; however, we did not find any differences in sweat rate as a result of cooling. Nevertheless, a reduced capability for sweating and lower aerobic capacity might feed forward to thermal perception and RPE. Therefore we recommend cautious application of our findings to females and encourage future research in this area.

\subsection{Recommendations}

Our analysis provides evidence that self-paced performance is improved when the cooling strategy is administered during continuous exercise before the performance trial. Ice slurry ingestion and neck cooling are the most studied practical cooling interventions and are both associated with beneficial effects on thermal perception, RPE and performance. We suggest that improvements in self- 
paced performance are mediated via the beneficial effects of cooling on thermal perception and RPE. This is consistent with human behavioural thermoregulatory theory [2], which states that self-selected intensity of exercise increases or decreases dependent on the magnitude of thermal or cardiovascular strain, which integrates with the predominant intensity controller, RPE. In principle, participants felt cooler during exercise and perceived the intensity of exercise to be less. Consequently, participants chose to increase external intensity, resulting in a performance improvement. This is clearly beneficial for highperformance athletes; however, it is associated with a risk of heat-related illness, particularly for novice and youth athletes, as an increased intensity causes a greater magnitude of metabolic heat production, heat storage and body temperature. This combination is of particular concern if the environment is uncompensable or the thermoregulatory responses of the participant are inadequate to equilibrate the basic heat balance equation [1].

Practitioners should also be aware relatively large volumes of ice slurry $(240 \mathrm{ml})$ or cold water ingestion $(>400 \mathrm{ml}$ ) might decrease sweat gland activity and limit the potential for evaporative heat loss, resulting in heat storage and high body temperature. This is another concern for underprepared novice and youth populations whose whole body sweat responses and evaporative heat transfer potential are likely inadequate to match that required to attain heat balance. Such a bolus, however, is associated with discomfort [32], and an ingestion of this magnitude would likely be avoided ad libitum. We are not aware of any meaningful detriment on whole body sweat rate occurring due to neck cooling; however, neck cooling is associated with the attainment of a high body temperature (Fig. 3). Indeed, none of the practical cooling methods were sufficient to attenuate an increase in body temperature. Therefore, we suggest practitioners undertake a thorough evaluation of the environment where competition or training will take place and that metabolic heat production and evaporative heat loss requirements are estimated prior to activity. Adequate body temperature, fluid balance and perceptual monitoring procedures [3, 55] should be in place, especially for highly motivated novice and youth athletes. Such an approach will improve the likelihood that appropriate cooling strategies are implemented during exercise. To date, no studies have investigated a combination of neck cooling, ice slurry and cold fluid ingestion; these strategies might have additive effects and be more beneficial than administering a single method alone. Future research should also consider exploiting sites, such as the hands, that have potential to attenuate increases in body temperature [56, 57]. In addition, opinions of coaches, athletes and support staff regarding the practicality of cooling methods should be evaluated to guide scientists towards research that has high ecological validity and sound mechanistic underpinning.

\section{Conclusion}

We found that practical cooling strategies administered during exercise before a self-paced endurance trial improve performance in hot environments, but not by decreasing core temperature as previously thought [18]. Instead we suggest that current methods improve performance by benefiting thermal perception and RPE, resulting in greater self-selected external intensities compared with a thermoneutral or no cooling trial, thus improving endurance performance. We encourage practitioners to explore the use of cold fluid, ice slurry ingestion and neck cooling for endurance performance enhancement after examining the thermal constraints of the environment. Future research should investigate a combination of approaches to cooling during continuous exercise as well as additional sites, such as the hands, that have the potential to attenuate increases in body temperature.

\section{Compliance with Ethical Standards}

Funding No funding or financial support was received to conduct this study.

Conflict of interest Alan Ruddock, Brent Robbins, Garry Tew, Liam Bourke and Alison Purvis declare they have no conflict of interest relevant to the content of this review.

Open Access This article is distributed under the terms of the Creative Commons Attribution 4.0 International License (http:// creativecommons.org/licenses/by/4.0/), which permits unrestricted use, distribution, and reproduction in any medium, provided you give appropriate credit to the original author(s) and the source, provide a link to the Creative Commons license, and indicate if changes were made.

\section{References}

1. Kenny GP, Jay O. Thermometry, calorimetry, and mean body temperature during heat stress. Compr Physiol. 2013;3:1689-719.

2. Flouris AD, Schlader ZJ. Human behavioral thermoregulation during exercise in the heat. Scand J Med Sci Sports. 2015;25:52-64.

3. Casa DJ, DeMartini JK, Bergeron MF, et al. National athletic trainers' association position statement: exertional heat illnesses. J Athl Train. 2015;50:986-1000.

4. Galloway SDR, Maughan RJ. Effects of ambient temperature on the capacity to perform prolonged cycle exercise in man. Med Sci Sports Exerc. 1997;29:124-1249.

5. González-Alonso J, Teller C, Andersen SL, et al. Influence of body temperature on the development of fatigue during prolonged exercise in the heat. J Appl Physiol. 1999;86:1032-9.

6. Parkin JM, Carey MF, Zhao S, et al. Effect of ambient temperature on human skeletal muscle metabolism during fatiguing submaximal exercise. J Appl Physiol. 1999;86:902-8. 
7. Tatterson AJ, Hahn AG, Martin DT, et al. Effect of heat stress on physiological responses and exercise performance in elite cyclists. J Sci Med Sport. 2000;3:186-93.

8. Tucker R, Rauch L, Harley YXR, et al. Impaired exercise performance in the heat is associated with an anticipatory reduction in skeletal muscle recruitment. Pflugers Arch. 2004;448:422-30.

9. Guy J, Deakin G, Edwards A, et al. Adaptation to hot environmental conditions: an exploration of the performance basis, procedures and future directions to optimise opportunities for elite athletes. Sports Med. 2014;45:303-11.

10. Ely BR, Cheuvront SN, Kenefick RW, et al. Aerobic performance is degraded, despite modest hyperthermia, in hot environments. Med Sci Sports Exerc. 2010;42:135-41.

11. Ely MR, Cheuvront SN, Roberts WO, et al. Impact of weather on marathon-running performance. Med Sci Sports Exerc. 2007;39:487-93.

12. Nybo L, Secher NH, Nielsen B. Inadequate heat release from the human brain during prolonged exercise with hyperthermia. J Physiol. 2002;545:697-704.

13. González-Alonso J, Calbet JA. Reductions in systemic and skeletal muscle blood flow and oxygen delivery limit maximal aerobic capacity in humans. Circulation. 2003;107:824-30.

14. Levels K, de Koning J, Broekhuijzen I, et al. Effects of radiant heat exposure on pacing pattern during a $15-\mathrm{km}$ cycling time trial. J Sports Sci. 2014;32:845-52.

15. Schlader ZJ, Perry BG, Jusoh MRC, et al. Human temperature regulation when given the opportunity to behave. Eur J Appl Physiol. 2013;113:1291-301.

16. Fukazawa T, Havenith G. Differences in comfort perception in relation to local and whole body skin wettedness. Eur J Appl Physiol. 2009;106:15-24.

17. Morante SM, Brotherhood JR. Thermoregulatory responses during competitive singles tennis. Br J Sports Med. 2008;42:736-41.

18. Bongers CCWG, Thijssen DHJ, Veltmeijer MTW, et al. Precooling and percooling (cooling during exercise) both improve performance in the heat: a meta-analytical review. Br J Sports Med. 2015;49:377-84.

19. Tyler CJ, Sunderland C, Cheung SS. The effect of cooling prior to and during exercise on exercise performance and capacity in the heat: a meta-analysis. Br J Sports Med. 2015;49:7-13.

20. Burdon CA, Connor HTO, Gifford JA, et al. Influence of beverage temperature on exercise performance in the heat: a systematic review. Int J Sport Nutr. 2010;20:166-74.

21. Siegel R, Laursen PB. Keeping your cool heat with internal cooling methods. Sports Med. 2012;42:89-98.

22. DeGroot DW, Gallimore RP, Thompson SM, et al. Extremity cooling for heat stress mitigation in military and occupational settings. J Therm Biol. 2013;38:305-10.

23. Seals DR. Translational physiology: from molecules to public health. J Physiol. 2013;591:3457-69.

24. Liberati A, Altman DG, Tetzlaff J, et al. The PRISMA statement for reporting systematic reviews and meta-analyses of studies that evaluate healthcare interventions explanation and elaboration. BMJ. 2009;339:b2700.

25. Higgins JPT, Altman DG, Gotzsche PC, et al. The Cochrane Collaboration's tool for assessing risk of bias in randomised trials. BMJ. 2011;343:d5928.

26. Burdon C, O'connor H, Gifford J, et al. Effect of drink temperature on core temperature and endurance cycling performance in warm, humid conditions. J Sports Sci. 2010;28:1147-56.

27. Burdon CA, Hoon MW, Johnson NA, et al. The effect of ice slushy ingestion and mouthwash on thermoregulation and endurance performance in the heat. Int $\mathrm{J}$ Sport Nutr Exerc. 2013;23:458-69.
28. Burdon CA, Ruell P, Johnson N, et al. The effect of ice-slushy consumption on plasma vasoactive intestinal peptide during prolonged exercise in the heat. J Therm Biol. 2015;47:59-62.

29. Lee JKW, Maughan RJ, Shirreffs SM. The influence of serial feeding of drinks at different temperatures on thermoregulatory responses during cycling. J Sports Sci. 2008;26:583-90.

30. Schulze E, Daanen H, Levels K, et al. Effect of thermal state and thermal comfort on cycling performance in the heat. Int J Sport Physiol Perform. 2015;10:655-63.

31. Lee JKW, Koh ACH, Koh SXT, et al. Neck cooling and cognitive performance following exercise-induced hyperthermia. Eur $\mathbf{J}$ Appl Physiol. 2014;114:375-84.

32. Morris NB, Coombs G, Jay O. Ice slurry ingestion leads to a lower net heat loss during exercise in the heat. Med Sci Sport Exerc. 2016;48:114-22.

33. Scheadler CM, Saunders NW, Hanson NJ, et al. Palm cooling does not improve running performance. Int $\mathrm{J}$ Sports Med. 2013;34:732-5.

34. Tyler CJ, Sunderland C. Cooling the neck region during exercise in the heat. J Athl Train. 2011;46:61-8.

35. Tyler CJ, Sunderland C. Neck cooling and running performance in the heat: single versus repeated application. Med Sci Sports Exerc. 2011;43:2388-95.

36. Tyler CJ, Wild P, Sunderland C. Practical neck cooling and timetrial running performance in a hot environment. Eur J Appl Physiol. 2010;110:1063-74.

37. Ramanathan NL. A new weighting system for mean surface temperature of the human body. J Appl Physiol. 1964;19:531-3.

38. Minniti A, Tyler CJ, Sunderland C. Effects of a cooling collar on affect, ratings of perceived exertion, and running performance in the heat. Eur J Sport Sci. 2011;11:419-29.

39. Bulbulian R, Shapiro R, Murphy M, Levenhagen D. Effectiveness of a commercial head-neck cooling device. J Strength Cond Res. 1999;13:198-205.

40. Young AJ, Sawka MN, Epstein Y, et al. Cooling different body surfaces during upper and lower body exercise. J Appl Physiol. 1987;63:1218-23.

41. Gagge AP, Stolwijk JA, Hardy J. Comfort and thermal sensations and associated physiological responses at various ambient temperatures. Environ Res. 1967;1:1-20.

42. Parsons K. Human thermal environments: the effects of hot, moderate, and cold environments on human health, comfort, and performance. 3rd ed. Boca Raton: CRC Press; 2014.

43. Carvalho M, de Andrade M, Ramos G, et al. The temperature of water ingested ad libitum does not influence performance during a 40-km self-paced cycling trial in the heat. J Sports Med Phys Fitness. 2015;55:1473-9.

44. Kenny GP, Schissler AR, Stapleton J, et al. Ice cooling vest on tolerance for exercise under uncompensable heat stress. J Occup Environ Hyg. 2011;8:484-91.

45. Mündel T, King J, Collacott E, et al. Drink temperature influences fluid intake and endurance capacity in men during exercise in a hot, dry environment. Exp Physiol. 2006;91:925-33.

46. Sawka MN, Leon LR, Montain SJ, et al. Integrated physiological mechanisms of exercise performance, adaptation, and maladaptation to heat stress. Compr Physiol. 2011;1:1883-928.

47. Ruddock AD, Tew GA, Purvis AJ. Reliability of intestinal temperature using an ingestible telemetry pill system during exercise in a hot environment. J Strength Cond Res. 2014;28:861-9.

48. Nybo L, Rasmussen P, Sawka MN. Performance in the heatphysiological factors of importance for hyperthermia-induced fatigue. Compr Physiol. 2014;4:657-89.

49. Currell K, Jeukendrup AE. Validity, reliability and sensitivity of measures of sporting performance. Sports Med. 2008;38: 297-316. 
50. Luomala MJ, Oksa J, Salmi JA, et al. Adding a cooling vest during cycling improves performance in warm and humid conditions. J Therm Biol. 2012;37:47-55.

51. Nybo L, González-Alonso J. Critical core temperature: a hypothesis too simplistic to explain hyperthermia-induced fatigue. Scand J Med Sci Sports. 2015;25:4-5.

52. Rowell LB. Human cardiovascular adjustments to exercise and thermal-stress. Physiol Rev. 1974;54:75-159.

53. Nakamura M, Yoda T, Crawshaw LI, et al. Relative importance of different surface regions for thermal comfort in humans. Eur $\mathbf{J}$ Appl Physiol. 2013;113:63-76.

54. Gagnon D, Kenny GP. Does sex have an independent effect on thermoeffector responses during exercise in the heat? J Physiol. 2012;590:5963-73.
55. Armstrong LE, Casa DJ, Millard-Stafford M, et al. American College of Sports Medicine position stand. Exertional heat illness during training and competition. Med Sci Sports Exerc. 2007;39:556-72.

56. Hsu AR, Hagobian TA, Jacobs KA, et al. Effects of heat removal through the hand on metabolism and performance during cycling exercise in the heat. Can J Appl Physiol. 2005;30:87-104.

57. Taylor NAS, Machado-Moreira CA, van den Heuvel AMJ, et al. Hands and feet: physiological insulators, radiators and evaporators. Eur J Appl Physiol. 2014;114:2037-60. 